\title{
Transforming Enterprise Architecture Models: An Artificial Ontology View
}

\author{
Sandeep Purao ${ }^{1}$, Richard Martin ${ }^{2}$, and Edward Robertson ${ }^{3}$ \\ ${ }^{1}$ College of Information Sciences \& Technology, Pennsylvania State University, PA 16802 \\ spurao@ist.psu.edu \\ ${ }^{2}$ Tinwisle Corp., Bloomington Indiana \\ richardmatinwisle.com \\ ${ }^{3}$ Indiana University and Persistent Systems Inc. \\ edrbtsn@indiana.edu
}

\begin{abstract}
Enterprise Architecture (EA) is, by definition, an artificial construct. It includes conceptual objects and attributes created for human purposes. EA models, therefore, require an ontological foundation that goes beyond the 'furniture of the world' metaphor. We develop an argument that supports this premise, and demonstrate how the perspective can help us understand operations on EA models. The paper demonstrates these operations with an example and briefly points to formalization efforts detailed elsewhere. The paper concludes with implications for research and practice.
\end{abstract}

Keywords: Enterprise Architecture, Artificial Ontology, Operations.

\section{Introduction}

Enterprise Architecture (EA) is the logic underlying a business (Ross et al. 2006). An EA outlines how the different technological, human and organizational elements within the business are structured, describes how they can be coordinated, and makes plain possibilities for manipulation for business improvements. Accurate yet mutable representations are, therefore, important for the practice of EA. These representations must also include not only the furniture of the world (Bunge 1977) but also conceptual constructs created for satisfying human goals (March and Allen 2007). Decisionmakers can use these representations to chart the course for an enterprise; managers can use these to communicate with stakeholders (Schekkerman 2008).

A number of meta-models, frameworks and standards have been suggested for EA representations (e.g. Zachman 1987, DoD 2010, ISO Standards 42010, 15704). The manner in which practitioners use these meta-models and frameworks, however, remains unclear. Their use of these meta-models and frameworks cannot be the same as that for conventional software engineering where the designers' aim is to move from models to executable software. In contrast, EA efforts often include an archaeological expedition with the intention of charting a new course of action for the enterprise and facilitating stakeholder buy-in.

The research reported in this paper is presented against the above backdrop. We explore an alternative ontological basis for EA models and identify transformations 
that capture how EA models are designed and used. The question we address is, therefore, the following: What are the operations on EA models following an artificial ontology view? The key contribution of our work is the development of these operations building on the ontology of the artificial (March and Allen 2007).

\section{Conceptual Models and Modeling for Enterprise Architecture}

Received wisdom for conceptual modeling for information systems (Wand and Weber 1990) builds on Bunge's (1977) ontology. It posits that conceptual models must show fidelity against the real-world they represent (Wand and Weber 2002). In contrast, EA practitioners use models for different purposes. Table 1 below summarizes the differences and Figure 1 outlines how EA models are used.

Table 1. Conceptual Models for Enterprise Architecture vs. Software

\begin{tabular}{|l|l|l|}
\hline Concern & Enterprise Architecture & Software Applications \\
\hline What & The underlying logic of a business & Structure and functionality of software \\
\hline When & $\begin{array}{l}\text { Often post-facto, after a business } \\
\text { model is in place in the organization }\end{array}$ & $\begin{array}{l}\text { Typically prior to the (detailed) design } \\
\text { and implementation of software }\end{array}$ \\
\hline How & $\begin{array}{l}\text { A reflection of the architecture as it } \\
\text { exists, and a vision of a desired state }\end{array}$ & $\begin{array}{l}\text { Often based on the intended software } \\
\text { implementation }\end{array}$ \\
\hline Who & $\begin{array}{l}\text { Provides a decision vehicle and } \\
\text { what-if model for decision-makers }\end{array}$ & $\begin{array}{l}\text { Translates user requirements into } \\
\text { designs for software developers }\end{array}$ \\
\hline Use & $\begin{array}{l}\text { A communication mechanism to } \\
\text { effect change }\end{array}$ & $\begin{array}{l}\text { Produce a functional software that meets } \\
\text { the requirements }\end{array}$ \\
\hline Life cycle & $\begin{array}{l}\text { Moving from extension to intension, } \\
\text { effecting change in both }\end{array}$ & $\begin{array}{l}\text { Moving from intension to extension in } \\
\text { spite of round-trip engineering }\end{array}$ \\
\hline Abstraction & $\begin{array}{l}\text { Explicit use and instantiation from } \\
\text { frameworks with multiple models }\end{array}$ & $\begin{array}{l}\text { Implicit re-use of the ontology or } \\
\text { domain models during design }\end{array}$ \\
\hline
\end{tabular}

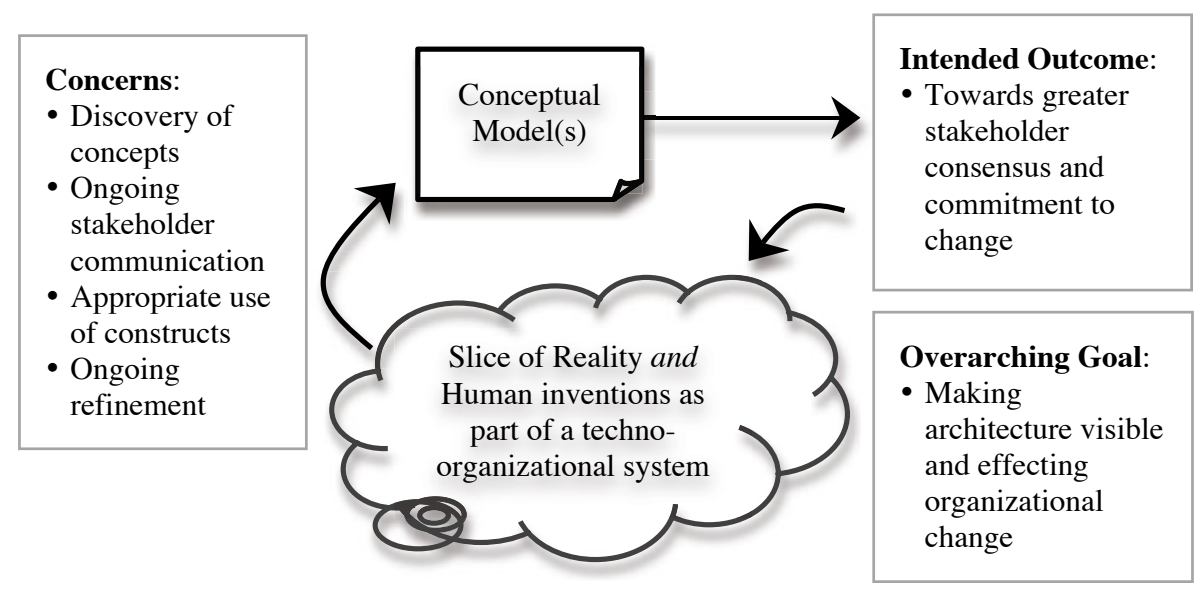

Fig. 1. Conceptual models and modeling for Enterprise Architecture 
These differences provide inspiration for the work we present in this paper. We start by proposing an alternative to Bunge's ontology.

\section{An Ontology of the Artificial}

An ontology of the artificial begins with the premise that although business enterprises "use concrete objects such as people, machines, and buildings to accomplish their goals; they are concerned primarily with the meaning and purpose ascribed to concrete and conceptual objects and with invented rules ..." (March and Allen 2007). As a result, it "accommodate[s] occurrences of conceptual events that form the basis of social phenomena" (March and Allen 2007).

\subsection{Fundamental Constructs}

The constructs underlying the ontology of the artificial extend those suggested by Wand and Weber (1990). Table 2 outlines these (March and Allen 2007).

Table 2. Constructs in the Ontology

\begin{tabular}{|l|l|}
\hline Construct & Elaboration \\
\hline $\begin{array}{l}\text { Objects: } \\
\text { Concrete }\end{array}$ & Exist physically \\
\hline $\begin{array}{l}\text { Objects: } \\
\text { Conceptual }\end{array}$ & Exist by human invention and social agreement (new) \\
\hline $\begin{array}{l}\text { Attributes: } \\
\text { Substantial }\end{array}$ & $\begin{array}{l}\text { Ascribed to concrete objects to represent human understanding of natural } \\
\text { phenomena }\end{array}$ \\
\hline $\begin{array}{l}\text { Attributes: } \\
\text { Invented }\end{array}$ & $\begin{array}{l}\text { Ascribed to concrete and conceptual objects to enable social discourse } \\
\text { (new). Can be used for individuation. }\end{array}$ \\
\hline $\begin{array}{l}\text { Types } \\
\text { (classes) }\end{array}$ & $\begin{array}{l}\text { Object grouped into Types based on ascription of one or more common } \\
\text { attributes }\end{array}$ \\
\hline $\begin{array}{l}\text { Status (of an } \\
\text { Object) }\end{array}$ & $\begin{array}{l}\text { Is the set of values of its attributes at a point in time; the history of an } \\
\text { object is the chronology of its status. }\end{array}$ \\
\hline $\begin{array}{l}\text { Events: } \\
\text { Concrete }\end{array}$ & $\begin{array}{l}\text { Effect changes to substantial properties of concrete objects; follow } \\
\text { immutable, natural, discoverable laws. }\end{array}$ \\
\hline $\begin{array}{l}\text { Event: } \\
\text { Conceptual }\end{array}$ & $\begin{array}{l}\text { Effect changes to invented attributes of concrete or conceptual objects, and } \\
\text { follow rules (designed by human agreement), which are mutable. (new) }\end{array}$ \\
\hline Relationship & $\begin{array}{l}\text { Objects affected by the same event are in a relationship with the event and } \\
\text { hence, in relationship to each other through the event. }\end{array}$ \\
\hline Decomposition & $\begin{array}{l}\text { Objects as well as Events may compose and decompose to form other } \\
\text { Objects or Events respectively. }\end{array}$ \\
\hline
\end{tabular}

March and Allen's (2007) proposal contains three new constructs. The conceptual objects and invented attributes allow addition of new objects and attributes as EA models are refined. The conceptual events allow negotiation of new modes of changes to objects and attributes, including a change in the stakeholders. Together, they allow possibilities for EA models. We use these to conceptualize operations on EA models. 


\section{Operations of EA Models}

We identify six operations on EA models: Projection, Instantiation, Specialization, Refinement, Derivation, and Linking. Table 3 summarizes the operations.

Table 3. Operations on EA Models*

\begin{tabular}{|l|l|}
\hline Operation & Description \\
\hline Projection & Transforming a (set of) objects by selecting a subset of attributes \\
\hline Instantiation & Creating a (set of) objects/events based on a construct in the meta-model \\
\hline Refinement & $\begin{array}{l}\text { Elaboration of a (set of) conceptual } \text { objects/events by addition of } \text { invented } \\
\text { attributes; Decomposition of a (set of) conceptual objects/events by } \\
\text { identifying component } \text { objects }\end{array}$ \\
\hline Specialization & Adding variations to a (set of) objects by adding invented attributes \\
\hline Derivation & $\begin{array}{l}\text { Manipulation of } \text { attributes of a (set of) objects to derive values for related } \\
\text { objects; Transformation of } \text { objects into other } \text { objects }\end{array}$ \\
\hline Linking & Establishing a connection between a (set of) objects/events \\
\hline
\end{tabular}

* Note: The description uses constructs from the ontology (see Table 2), shown in italics.

\subsection{Projection}

Projection $(\mathrm{P})$ refers to the transforming of an object into a form that consists only of those properties that a stakeholder requires. It is analogous to the existential quantification operation in predicate logic. The essential characteristic of Projection is discarding some information as a surjective and unary operation while preserving 'type'. Consider, for example, a shipping container manufacturer who uses a corrugating machine to produce a range of cardboard stock that must be cut, printed, folded, and glued on many machines to meet particular customer specifications. A Projection may involve extracting information related to machine capacities to structure a conveyance system that accumulates and forwards the stock to the appropriate printer and box machines.

\subsection{Instantiation}

Instantiation (I) is a constructive step. It adds the detail necessary for constructing a reification of a concept. For concrete entities, this can lead to tangible things in the world. For conceptual entities, instantiation can require assigning values to invented attributes. During the EA cycle, instantiation may first occur for the purpose of constructing an EA model from the framework or standard. A second level of instantiation may occur during the mapping and use of the EA model against specific instances of an Activity or Node. Instantiation of the first kind takes place during the design phase, whereas the second kind takes place during use of the EA models.

\subsection{Refinement}

Refinement $(\mathrm{R})$ is an information adding operation. The essential characteristic of Refinement is the preservation of boundary. During an EA life cycle, Refinement is critical because it allows addition of information beyond the original creation of an 
object. It acknowledges that it is not feasible to fully specify the structure of an object upon its creation because of inputs needed from multiple stakeholders, and because of the artificial nature of the object itself. Refinement can occur via decomposition or elaboration. For example, one can refine the understanding of an automobile engine in two ways: adding facts about engine features, e.g. the displacement or horsepower (refinement); or exposing sub-components, e.g. block, head, and pistons (decomposition). Elaboration may require addition of Invented Attributes enhancing commitment from stakeholders; decomposition may result in addition of Conceptual Objects or Events providing a way to scale down commitment.

\subsection{Specialization}

Specialization (S) is the construction of variations on the basis of Concrete or Conceptual objects. It corresponds to the idea of creating sub-classes. It is qualitatively different from Elaboration in that Specialization involves spawning new objects that are still within the boundaries specified by the source object. Consider, for example, a global producer of manufactured products with customers in different countries. Each may have different trade rules regarding import tariffs. Here, Specialization may be applied to the object Country to distinguish between non-tariff countries and tariff countries by identifying and including different attributes that are part of each new object. During the EA life cycle, Specialization can help different stakeholders negotiate their spheres of responsibility.

\subsection{Derivation}

Derivation (D) refers to the changing of the form of one or more elements without changing its content. It is a critical operation during the EA life cycle because it goes beyond Specialization or Refinement. Unlike these two, Derivation allows manipulation of specific attributes, including attributes from multiple objects without the need to generate a new Object or a permanent elaboration of an Object. It allows stakeholders to combine attributes from a number of related Objects in response to their information needs. As an example, consider the derivation of elements necessary for an ISO 19439 (ISO 2006) model description from a Zachman Framework description. Derivation may also involve computation of aggregates based on values of attributes from component objects or attributes from other related objects.

\subsection{Linking}

Linking (L) is the idea that elements - Concrete and Conceptual Objects, Concrete and Conceptual Events - may be connected via arbitrary associations. The need for links arises because EA models can contain representations at different levels of abstraction. Consider, for example, the creation of a link within a meta-level or across meta-levels or between components in a part hierarchy. The transformations resulting from links are often implicit or unstated. The link between a process and the role that is going to be responsible for completion of that process transforms the process into a managed activity. The linking may also be the result of a business rule applied during a refinement in the architecture model. 
The operations have been formalized. Further details of the formalization are available elsewhere (Martin et al. 2011).

\section{Application}

This section demonstrates their application to a case (adapted from Sessions 2007). The case describes an organization, MedAMore, that owns a regional chain of drugstores with a software package, MedAManage, consisting of three modules: M/Store, to run at the drug store; M/Warehouse, to run in a regional warehouse; and $\mathrm{M} / \mathrm{Home}$, to run at the home office. As the result of acquiring three regional chains, the software package has become an obstacle. M/Store now requires specializations such as regional insurance plans; M/Warehouse must reflect practices at regional warehouses; and the information-sharing approach cannot scale to the now 200 drugstores and regional offices. Upgrading is difficult because each module is large. The technical problems have created internal conflicts. The business side wants to acquire two more chains while IT was struggling to bring existing acquisitions online. EA is now being considered as a possible mechanism to build stronger partnerships across IT and business groups. Table 4 illustrates the operations on EA models that can help achieve these potentially stronger partnerships with the above case description.

Table 4. Illustrating operations with MedAMore

\begin{tabular}{|c|c|}
\hline Operation & Described in the MedAMore Case \\
\hline Projection & $\begin{array}{l}\text { - Making intended consequences of IT investment decisions visible to the } \\
\text { business stakeholders; making financial implications of IT investments } \\
\text { visible to the Finance function. }\end{array}$ \\
\hline Instantiation & $\begin{array}{l}\text { - Constructing instances of elements in the framework, e.g. creating } \\
\text { instances such as activity and object; and instantiating these, e.g. creating } \\
\text { instances of Activity such as 'Data cleansing for pharmacy orders.' }\end{array}$ \\
\hline Refinement & $\begin{array}{l}\text { - Elaboration and Decomposition by adding new attributes to track the } \\
\text { impact of IT investment decisions: investigation of financial impact and } \\
\text { impact on IT infrastructure. }\end{array}$ \\
\hline Specialization & $\begin{array}{l}\text { - Generating regional or store-specific specialization for practices and } \\
\text { modules. Distinguishing these based on criteria such as insurance plans } \\
\text { or region resulting in changes to modules and reporting structure. }\end{array}$ \\
\hline Derivation & $\begin{array}{l}\text { - Transforming models specified by stakeholders into detailed } \\
\text { requirements. Deriving information from these models about the impacts } \\
\text { of IT investments for affects on different portions of the IT infrastructure. }\end{array}$ \\
\hline Linking & $\begin{array}{l}\text { - Linking operational views of business processes to design decisions, to } \\
\text { organizational structure decisions, and IT investment decisions. Links } \\
\text { traversed to understand impact of IT investments on business operations. }\end{array}$ \\
\hline
\end{tabular}

The example demonstrates how the operations can help understand design and use of EA models. We acknowledge that this does not constitute validation. We use the example as a demonstration, similar to the suggestion by Hevner et al (2004). 


\section{Discussion}

Much prior research shows that EA models are realized through a series of actions by stakeholders, who not only design the models but also use them to transform the enterprise. The operations described in the paper emphasize this dual nature by capturing the evolutionary aspects of EA models. They build on the ontology of the artificial as a foundation, and allow explicit acknowledgement of the progression of EA models in practice (see, e.g. Grossman 2003; Ross et al 2006). Table 5 reconnects the arguments so far to the unique aspects of EA models.

Table 5. The Use of Operations for Conceptual Models of EA (see Table 1)

\begin{tabular}{|c|c|c|}
\hline Dimension & Enterprise Architecture & Use of Operations \\
\hline What & $\begin{array}{l}\text { The underlying logic of a } \\
\text { business }\end{array}$ & $\begin{array}{l}\text { Difficult to specify up-front, must evolve; } \\
\text { also stakeholders can have different } \\
\text { views: Refinement and Specialization }\end{array}$ \\
\hline When & $\begin{array}{l}\text { Often post-facto, after a business } \\
\text { model is in place in the } \\
\text { organization }\end{array}$ & $\begin{array}{l}\text { Refinement and Linking allows multiple } \\
\text { stakeholders to take part in the definition } \\
\text { and evolution of EA models }\end{array}$ \\
\hline How & $\begin{array}{l}\text { A reflection of the architecture } \\
\text { as it currently exists, and with a } \\
\text { vision of a desired state }\end{array}$ & $\begin{array}{l}\text { Decomposition and Specialization } \\
\text { allows fixing responsibility and allowing } \\
\text { stakeholders to participate in modeling }\end{array}$ \\
\hline Who & $\begin{array}{l}\text { Provides a decision vehicle and } \\
\text { what-if model for the } \\
\text { decision-makers }\end{array}$ & $\begin{array}{l}\text { Decomposition and Derivation can be } \\
\text { useful to communicate with different } \\
\text { stakeholders }\end{array}$ \\
\hline Use & $\begin{array}{l}\text { Used as a communication } \\
\text { mechanism to effect change } \\
\text { among stakeholders }\end{array}$ & $\begin{array}{l}\text { Projection allows stakeholders to use and } \\
\text { vary the different views of EA models } \\
\text { and use Linking to ensure consistency }\end{array}$ \\
\hline Life cycle & $\begin{array}{l}\text { Moving from extension to } \\
\text { intension, effecting change in } \\
\text { both via iterations }\end{array}$ & $\begin{array}{l}\text { Multiple levels of Instantiation including } \\
\text { their reversal allows stakeholders to } \\
\text { refine EA models }\end{array}$ \\
\hline Abstraction & $\begin{array}{l}\text { Explicit use and instantiation } \\
\text { from frameworks with multiple } \\
\text { models; for ensuring compliance }\end{array}$ & $\begin{array}{l}\text { Use of frameworks along with } \\
\text { Instantiation and Derivation allows } \\
\text { consistency across EA models }\end{array}$ \\
\hline
\end{tabular}

We do not argue that the operations are complete. Arguing completeness will require greater scrutiny, and understanding of how the operations are carried out in practice. Our intent is to distinguish the different modes of action by stakeholders across the EA life cycle (see, e.g. Smolander et al. 2008).

This paper has argued for appropriateness of an ontology of the artificial for EA modeling. To the best of our knowledge, no prior work has unpacked the space of transformations that represent these changes in EA models. Our intent in describing these operations is not to provide a formal basis for their automation. Instead, we seek to identify these operations as a way to better understand the decisions and actions of stakeholders involved in the design and use of EA models. We hope that the operations we have identified can provide a foundation for further studies such as the locality of impact, traversing abstractions or construction of macros (e.g. Martin and Robertson 2008) and identification of evolution patterns, backed by empirical studies. 


\section{References}

[1] Bunge, M.: Ontology: the furniture of the world. Springer, Heidelberg (1977)

[2] DoD Deputy Chief Information Officer (2010), DODAF Overview and Supporting Materials, http://cio-nii.defense.gov/sites/dodaf20/index.html (retrieved May 3, 2010)

[3] Grossman, I., Application of the NOAA Federated IT Enterprise Architecture Process. Government Enterprise Architecture Conference, June 2003.

[4] Hevner, A., et al.: Design Science Research in Information Systems. MIS Quarterly 28(1), 75-105 (2004)

[5] ISO 2000. International Organization for Standardization: Industrial Automation Systems - Requirements for Enterprise-Reference Architecture and Methodologies, ISO 15704:2000 (2000), http: / / www . iso.ch

[6] ISO 2006. International Organization for Standardization: Enterprise integration - framework for enterprise modeling, ISO 19439:2006 (2006), http: / /www . iso. ch

[7] ISO 2010 International Organization for Standardization: Systems and Software Engineering - Architecture Description (ISO/IEC CD1 42010) (2010), http: / / www . iso. ch (draft version of January 2010)

[8] March, S., Allen, G.: Challenges in Requirements Engineering: A Research Agenda for Conceptual Modeling. In: Design Requirements Workshop, Cleveland, OH, USA, June 36 (2007)

[9] Martin, R., Robertson, E.: Meta-matters. In: International Conference on Information Resources Management, Niagara Falls, Ontario (2008)

[10] Martin, R., Robertson, E., Purao, S.: Tracking Transformations in Enterprise Architecture Development. Working Paper (2011)

[11] McGann, T., Lyytinen, K.: How Information Systems Evolve by and for Use, Case Western Reserve University, USA. Sprouts: Working Papers on Information Systems 5(15) (2005), http: //sprouts . aisnet.org/5-15

[12] Ross, J., Weill, P., Robertson, D.: Enterprise Architecture as Strategy. Harvard Business Press, Boston (2006)

[13] Schekkerman, J.: Enterprise Architecture Good Practices Guide: How to Manage the Enterprise Architecture Practice. Trafford Publishing (2008)

[14] Sessions, R., A comparison of top four enterprise integration methodologies (2007), http: //msdn.microsoft.com/en-us/library/bb466232.aspx (retrieved 3 May 3, 2010)

[15] Smolander, K., Rossi, M., Purao, S.: Software architectures: Blueprint, literature, language or decision? European Journal of Information Systems, 114 (2008)

[16] Wand, Y., Weber, R.: An ontological model of an information system. IEEE Transactions on Software Engineering 16(11), 1282-1292 (1990)

[17] Wand, Y., Weber, R.: Research Commentary: Information Systems and Conceptual Modeling - A Research Agenda. Information Systems Research 13(4), 363-376 (2002)

[18] Zachman, J.: A framework for information systems architecture. IBM Systems Journal 26(3) (1987) 